\title{
Curing Kinetics and Viscosity Change of a Two-Part Epoxy Resin During Mold Filling in Resin-Transfer Molding Process
}

\author{
CHANG-LUN LEE, KUNG-HWA WEI \\ Department of Materials Science and Engineering, National Chiao Tung University, Hsinchu, 30049, Taiwan, \\ Republic of China
}

Received 28 June 1999; accepted 23 October 1999

\begin{abstract}
The curing kinetics and the resulting viscosity change of a two-part epoxy/ amine resin during the mold-filling process of resin-transfer molding (RTM) of composites was investigated. The curing kinetics of the epoxy/amine resin was analyzed in both the dynamic and the isothermal modes with differential scanning calorimetry (DSC). The dynamic viscosity of the resin at the same temperature as in the mold-filling process was measured. The curing kinetics of the resin was described by a modified Kamal kinetic model, accounting for the autocatalytic and the diffusion-control effect. An empirical model correlated the resin viscosity with temperature and the degree of cure was obtained. Predictions of the rate of reaction and the resulting viscosity change by the modified Kamal model and by the empirical model agreed well with the experimental data, respectively, over the temperature range $50-80^{\circ} \mathrm{C}$ and up to the degree of cure $\alpha=0.4$, which are suitable for the mold-filling stage in the RTM process. () 2000 John Wiley \& Sons, Inc. J Appl Polym Sci 77: 2139-2148, 2000
\end{abstract}

Key words: epoxy; kinetics; DSC; viscosity; resin transfer molding (RTM)

\section{INTRODUCTION}

The increasing use of polymer composites in the aerospace industry and in commercial applications has created the need for efficient fabrications of fiber-reinforced composites. ${ }^{1,2}$ Resintransfer molding (RTM) of fiber composites promises to be a cost-effective process for producing composite parts with exceptional strength and complex geometry. ${ }^{3-5}$ Using RTM can avoid problems of prepreg preparation, storage, and layup as encountered in the traditional autoclave process. RTM processes involve the introduction of a reactive resin over a short time into a closed mold containing preplaced fabric preforms, then fol-

Correspondence to: K.-H. Wei.

Contract grant sponsor: National Science Council of Taiwan, Republic of China; contract grant number: NSC 87-2623-D-009-005.

Journal of Applied Polymer Science, Vol. 77, 2139-2148 (2000)

() 2000 John Wiley \& Sons, Inc. lowed by curing of the resin. ${ }^{4,5} \mathrm{~A}$ heated mold is generally used to facilitate the mold filling and fiber impregnation. Thus, during mold filling, the inception of a chemical reaction in the resin takes place, and the resultant resin viscosity increases with filling time. High-performance composite parts require high fiber fractions and long flow paths, which results in a large flow resistance and extremely long mold-filling times. Consequently, a premature gelation of the resin may occur and leads to an incomplete mold filling. Therefore, accurate prediction and precise control of the resin viscosity in the mold-filling process is critical for achieving product consistency and process efficiency. The viscosity of the resin depends on the temperature and the reaction kinetics. A complete characterization of the reaction kinetics and the viscosity change of the resin during the moldfilling stage can provide useful information on the relation between the processing variables and the material properties. Resin curing with accompa- 
nying significant viscosity changes during the impregnation phase is the main issue affecting the processing of RTM parts. ${ }^{6,7}$ A proper mold design and a good process simulation require an accurate description of the reaction kinetics and the rheological behavior of the resin during the moldfilling stage.

Epoxy resin has gained wide acceptance as the prime matrix resin for high-performance fiberreinforced composites because it possess a combination of properties such as good thermal, chemical, and abrasion resistance and good adhesion. A general autocatalytic kinetic model was developed for describing the curing of epoxy resin in the autoclave processing of polymer composites. ${ }^{8-10}$ A diffusion-controlled rate constant $K_{d}{ }^{11}$ a diffusion factor, ${ }^{12,13}$ and a temperature-dependent function, $\alpha_{\max }$ (refs. 14 and 15) were incorporated into the model to account for the diffusion-control behavior at the latter stages of the cure reaction. Additionally, various expressions relating the change in viscosity to temperature and the extent of the cure reaction have been developed for composites processing. $9,10,14,16,17$ Although a number of flow models of mold filling in RTM are available, ${ }^{18-20}$ they often do not address the chemical reaction in the mold-filling process. The chemical reaction and the rheology of polyester, vinyl ester, and polyurethane during the mold-filling process were studied. ${ }^{6,7,16,21}$ However, only limited information can be found regarding the cure reaction and viscosity change of the epoxy resin during the filling stage of the RTM process. ${ }^{22}$ Therefore, further studies on the chemical interaction aspects of the RTM process is necessary to obtain information for process simulation and making appropriate choices of process variables.

In our previous study, ${ }^{23}$ a kinetic model describing both the mold filling and the final curing stage of a one-part high-performance epoxy in the RTM process was developed. The suitable temperature range for the model was between 160 and $197^{\circ} \mathrm{C}$. The objective of this study was to characterize the curing kinetics and the viscosity of a two-part epoxy/amine resin in the temperature range $50-80^{\circ} \mathrm{C}$ suitable for the filling stage of the RTM process. A modified $\mathrm{Kamal}^{8}$ kinetic model was used to describe the curing reaction taking place during the filling process. The resultant viscosity change of the resin in the impregnation process of the RTM is also described by an empirical model based on the results of the kinetic analysis.
Table I Properties of LY564/HY2954 Resin

\begin{tabular}{lc}
\hline \multicolumn{1}{c}{ Items } & Properties \\
\hline Mix ratio LY564 : HY2954 (parts & \\
by weight) & $100: 35$ \\
Viscosity (mPa s) at $25^{\circ} \mathrm{C}$ & 617 \\
Minimum viscosity (mPa s) at & 272 \\
$70^{\circ} \mathrm{C}$ & \\
Reference time (min) to $1500 \mathrm{mPa}$ & 150 \\
$\mathrm{~s}$ at $25^{\circ} \mathrm{C}$ & 12 \\
Gel time (min) at $140^{\circ} \mathrm{C}$ & 1.14 \\
Specific gravity of cured resin & 77 \\
Cured neat resin data & \\
Tensile strength $(\mathrm{Mpa})$ & 2.6 \\
Tensile modulus $(\mathrm{GPa})$ & 5.0 \\
Tensile strain $(\%)$ & 0.35 \\
Poisson's ratio & \\
Glass transition temperature & 147 \\
$\quad\left({ }^{\circ} \mathrm{C}\right)$ & 0.23 \\
Water absorption $(\%)$ & \\
(After 10 days immersion in & \\
$23^{\circ} \mathrm{C}$ water) &
\end{tabular}

Ciba-Geigy LY564/HY2954 is a two-part epoxy resin in which LY564 is the base resin of a bisphenol A epoxy containing reactive diluent and HY2954 is the hardener of 3,3'-dimethyl-4,4'-diamino-dicyclohexyl methane.

${ }^{a}$ From Ciba-Geigy data sheet.

\section{EXPERIMENTAL}

\section{Materials}

The resin used is a two-part epoxy/amine resin, LY564/HY2954, from Ciba-Geigy (Hawthorne, NY). LY564 is the base resin of a bisphenol A epoxy containing a reactive diluent. HY2954 is a hardener of 3,3'-dimethyl-4,4'-diaminodicyclohexyl methane. Detailed information of the resin can be found in Table I.

\section{Resin Kinetics}

A DuPont Model 2910 differential scanning calorimetry (DSC) and a TA Instruments thermal analyzer 2100 system were used to analyze the reaction kinetics of the LY564/HY2954 epoxy/ amine resin by assuming proportionality between the heat evolved during the cure and the extent of the reaction. Samples of $5-20 \mathrm{mg}$ weight were sealed in hermetic pans and heated from 25 to $330^{\circ} \mathrm{C}$ at a rate of $2,5,7,10$, and $20^{\circ} \mathrm{C} / \mathrm{min}$ for the dynamic scanning test. Isothermal DSC experiments were conducted at $50,60,70$, and $80^{\circ} \mathrm{C}$.

\section{Rheological Measurements}

A Rheometrics mechanical spectrometer (RMS605 ) in the oscillatory mode was used to evaluate 


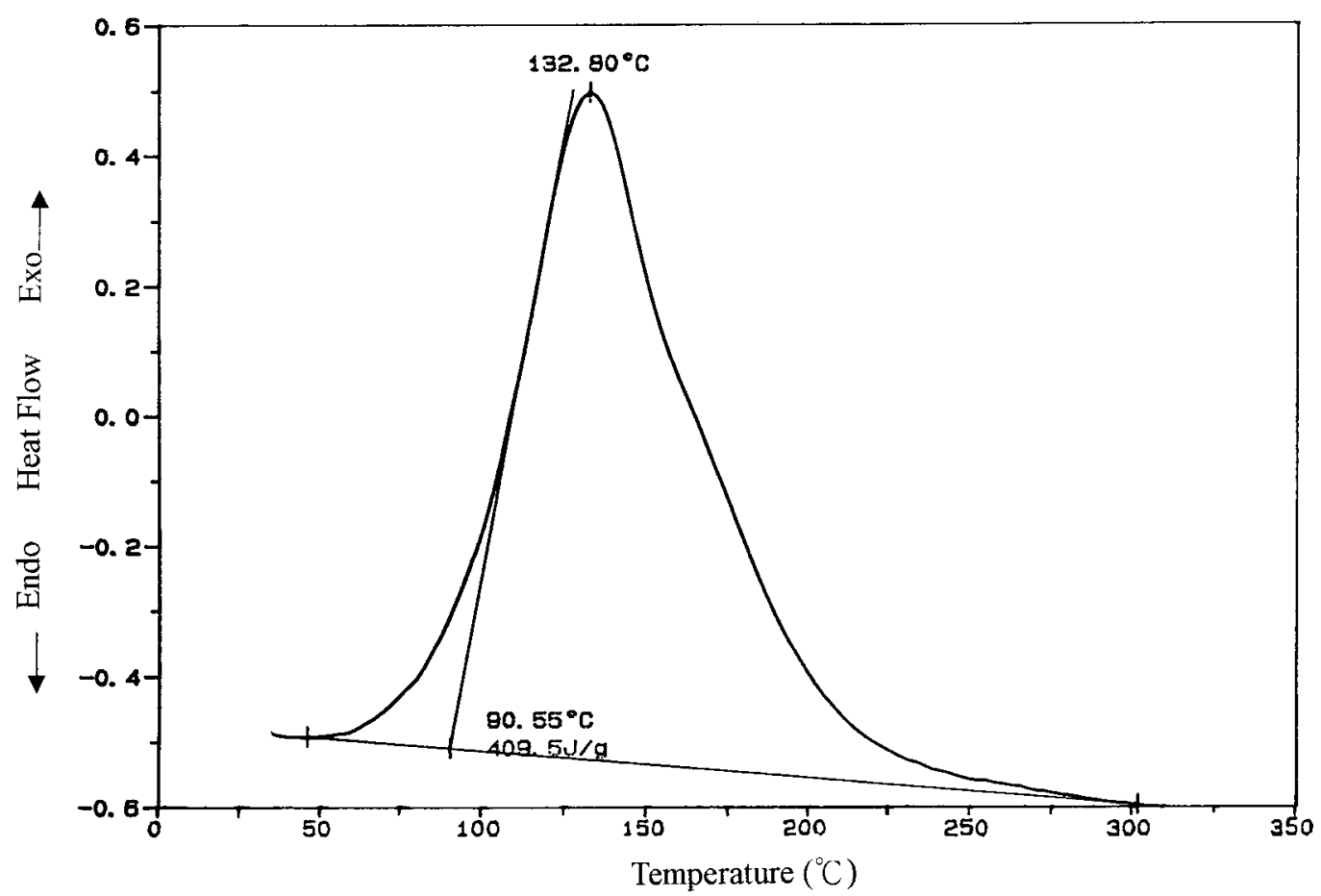

Figure 1 DSC thermogram in dynamic mode at a heating rate of $10^{\circ} \mathrm{C} / \mathrm{min}$.

the viscosity changes and the gelation that took place during the filling process in accordance to the specification of ASTM D 4473. Measurements were made using 25-mm-diameter disposable parallel plates subjected to forced oscillations with a gap of $0.5 \mathrm{~mm}$. An initial frequency of 10 $\mathrm{Hz}$ and an initial strain of $0.1 \%$ were applied to perform the isothermal measurements over the temperature range of $50-80^{\circ} \mathrm{C}$ with $10^{\circ} \mathrm{C}$ intervals. The gelation of the sample was assumed to be at the point at which the storage modulus $\left(\mathrm{G}^{\prime}\right)$ and the loss modulus $\left(\mathrm{G}^{\prime \prime}\right)$ intersected.

\section{RESULTS AND DISCUSSION}

\section{Reaction Kinetics}

In the kinetic studies by differential scanning calorimetry (DSC), it is assumed that the heat of reaction, $d H(t)$, is proportional to the degree of cure, $\alpha$. The rate of the reaction, $d \alpha / d t$, as a function of time can be calculated from the rate of heat flow evolved during the curing reaction:

$$
\alpha=\frac{H(t)}{H_{U}}
$$

$$
\frac{d \alpha}{d t}=\frac{1}{H_{U}} \frac{d H(t)}{d t}
$$

where $H_{U}$ is the average total heat of the reaction measured in the dynamic DSC tests, and $H(t)$, the area under an isothermal DSC curve up to time $t$. The dynamic DSC thermograms of the LY564/ HY2954 epoxy resin at a heating rate of $10^{\circ} \mathrm{C} / \mathrm{min}$ is shown in Figure 1. In Figure 1, the marked exothermic peak represented the curing reaction with the onset and the peak temperature at 90.55 and $132.80^{\circ} \mathrm{C}$, respectively. The average total heat of the reaction, $H_{U}$, measured at five different heating rates was found to be $405.3 \pm 11.1$ $\mathrm{J} / \mathrm{g}$. The cure reaction started at $48^{\circ} \mathrm{C}$ and became pronounced at $90.55^{\circ} \mathrm{C}$. Thus, the isothermal DSC measurements of the resin were conducted between 50 and $80^{\circ} \mathrm{C}$ with a $10^{\circ} \mathrm{C}$ interval, which is the temperature range suitable for the mold filling of the RTM process.

The reaction rate $d \alpha / d t$ as a function of time at these four different temperatures is displayed in Figure 2. In Figure 2, the reaction rate increases with time initially and decreases after passing through a maximum. The maximum peak height of the reaction rate increased with increasing temperature. The increase in temperature facilitated the curing reaction and the maximum of 


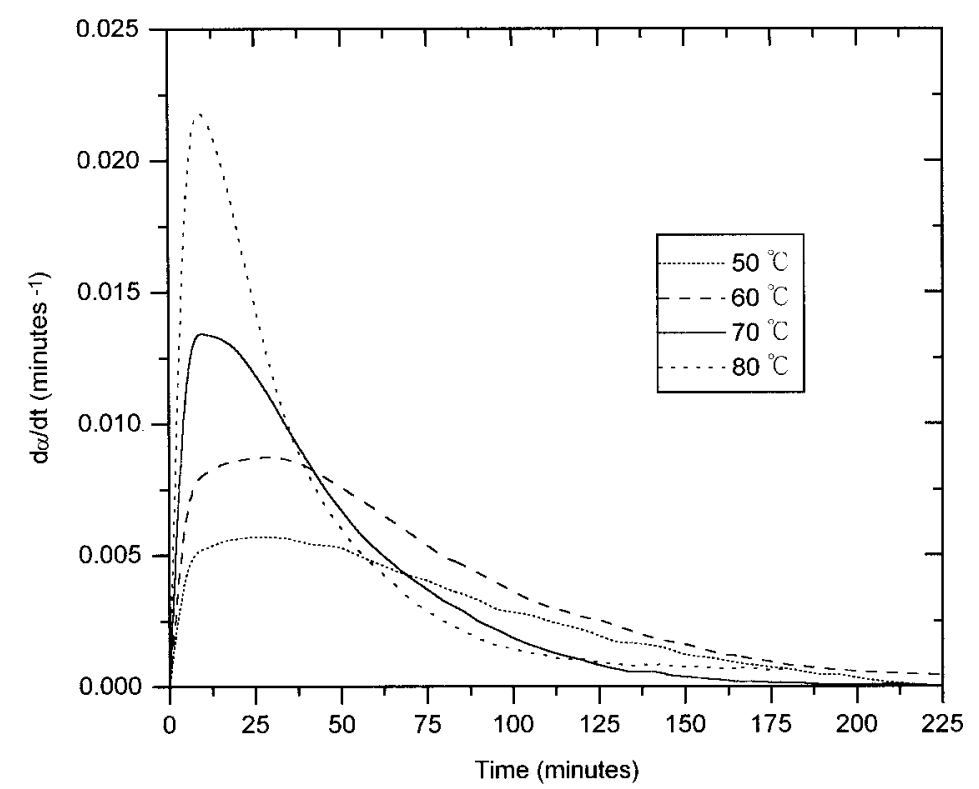

Figure 2 Reactin rate, $d \alpha / d t$, versus time for different curing temperatures.

reaction rate $d \alpha / d t$ did not occur at the onset of the reaction, indicating the autocatalytic effect of hydroxyl groups in curing of the epoxy resin. ${ }^{11}$ After passing through this maximum, the reaction rate decreases in such a way that it depends on the curing temperature. This decrease can be attributed to the diffusion process in the latter stages of the epoxy cure, ${ }^{24}$ because the cure cannot continue without the diffusion of low molecular weight species. The total amount of heat generated at a given temperature was termed the isothermal heat of reaction, $H_{T}$. The maximum degree of cure, $\alpha_{\max }$, which is defined as the ratio $H_{T} / H_{U}$, was found to be a function of temperature, as shown in Figure 3. It is evident that the curing reaction is not completed at any of the test temperatures owing to the diffusion control in the latter stage of the cure reaction. The maximum degree of cure, $\alpha_{\max }$, depends linearly on the cure temperature:

$$
\alpha_{\max }=0.2329+0.0017 T \times(K)
$$

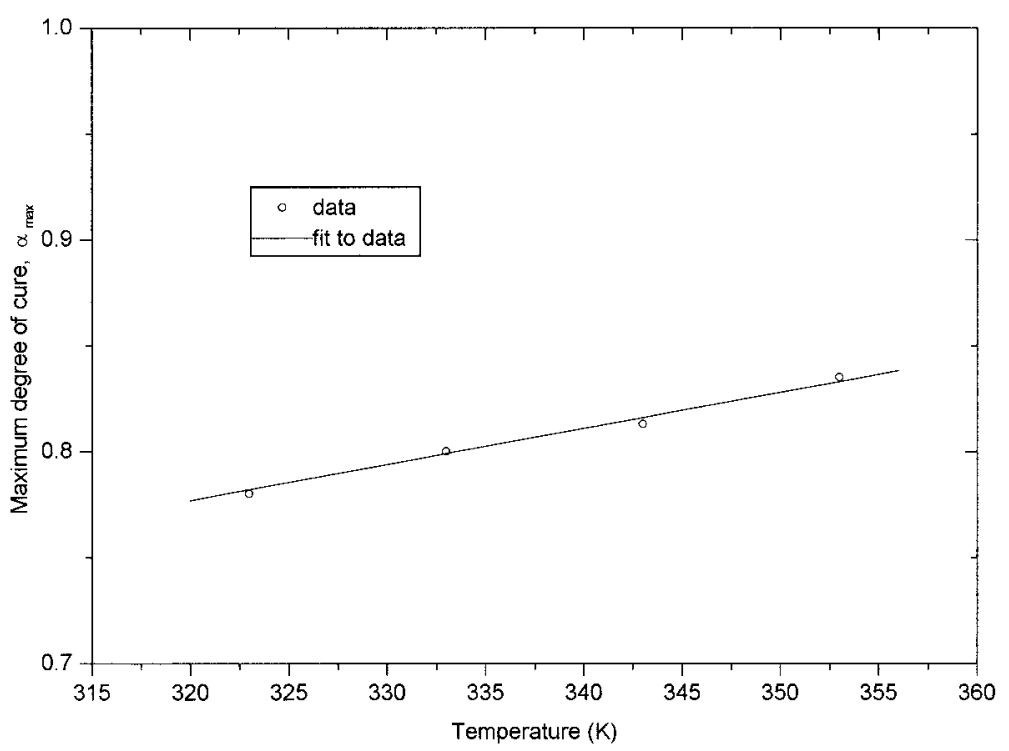

Figure 3 Temperature dependence of the maximum degree of cure, $\alpha_{\max }$. 


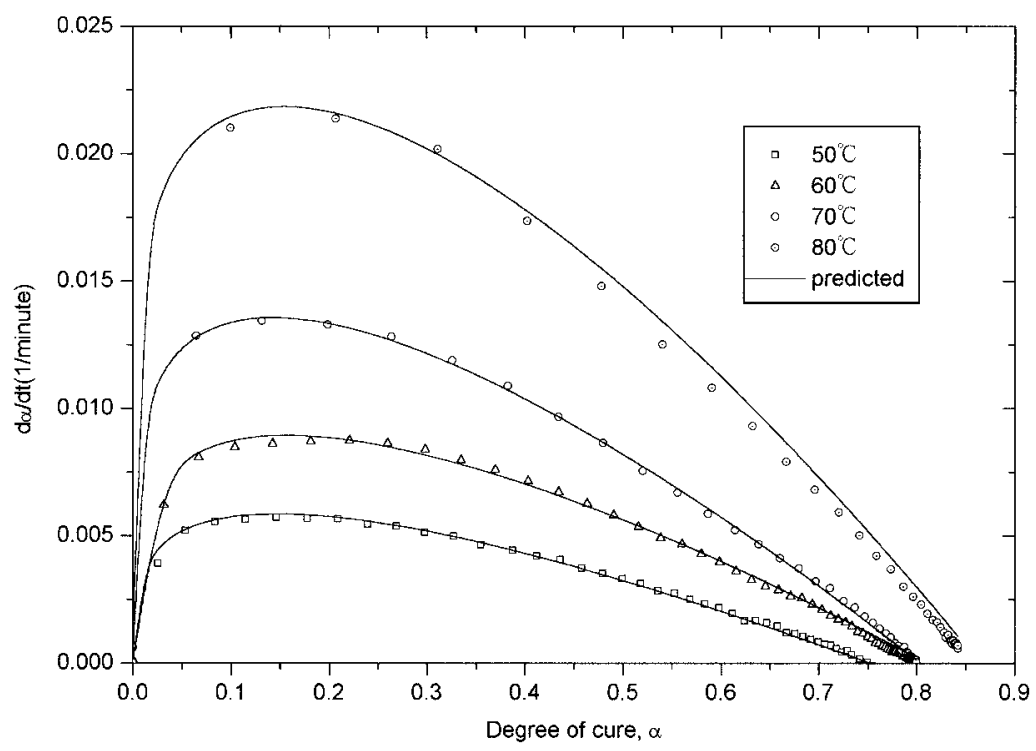

Figure 4 Comparisons of experimental data with predictions by autocatalytic model: reaction rate, $d \alpha / d t$, versus degree of cure, $\alpha$, at different temperatures.

Therefore, the maximum degree of cure, $\alpha_{\max }$, obtained at a given temperature is introduced into the Kamal expression of reaction kinetics ${ }^{8}$ to account for the autocatalytic curing behavior in the early stage and the diffusion-control process in the latter stage of the epoxy curing reaction:

$$
\frac{d \alpha}{d t}=\left(K_{1}+K_{2} \alpha^{m}\right)\left(\alpha_{\max }-\alpha\right)^{n}
$$

in which $m$ and $n$ represent the reaction orders.

The rate constants $K_{1}$ and $K_{2}$ depend on the temperature and correspond to the catalysis by hydroxyl groups initially present in the epoxy resin and the catalysis by hydroxyl groups formed in the curing reaction, ${ }^{11}$ respectively. $K_{1}$ and $K_{2}$ can be expressed in terms of the Arrhenius expression:

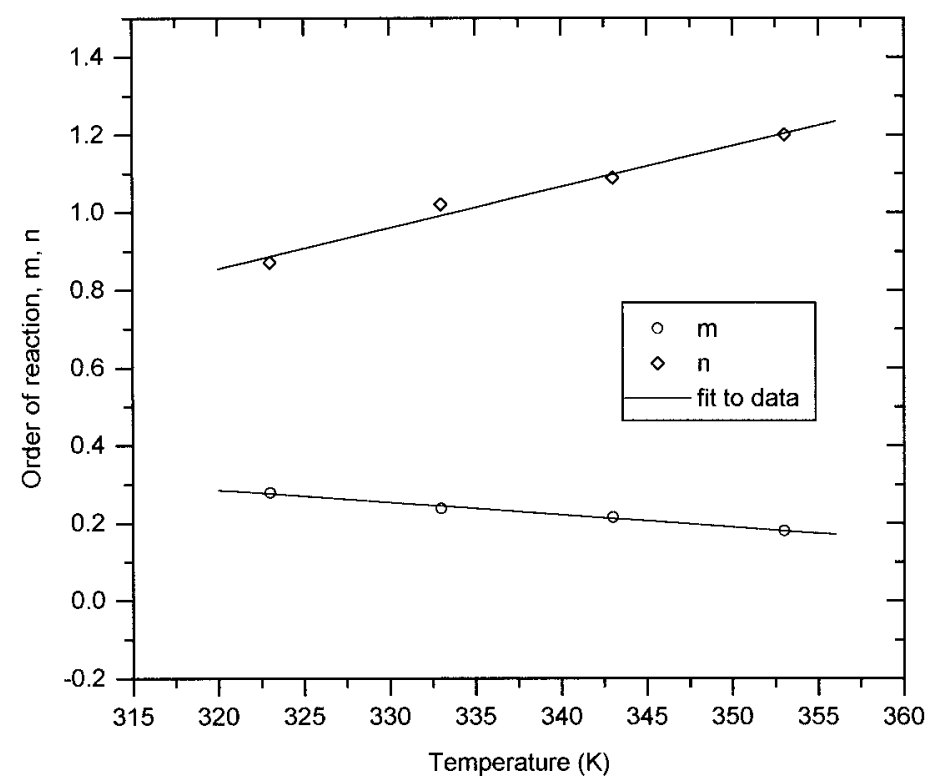

Figure 5 Reaction orders $m$ and $n$ as a function of temperature. 


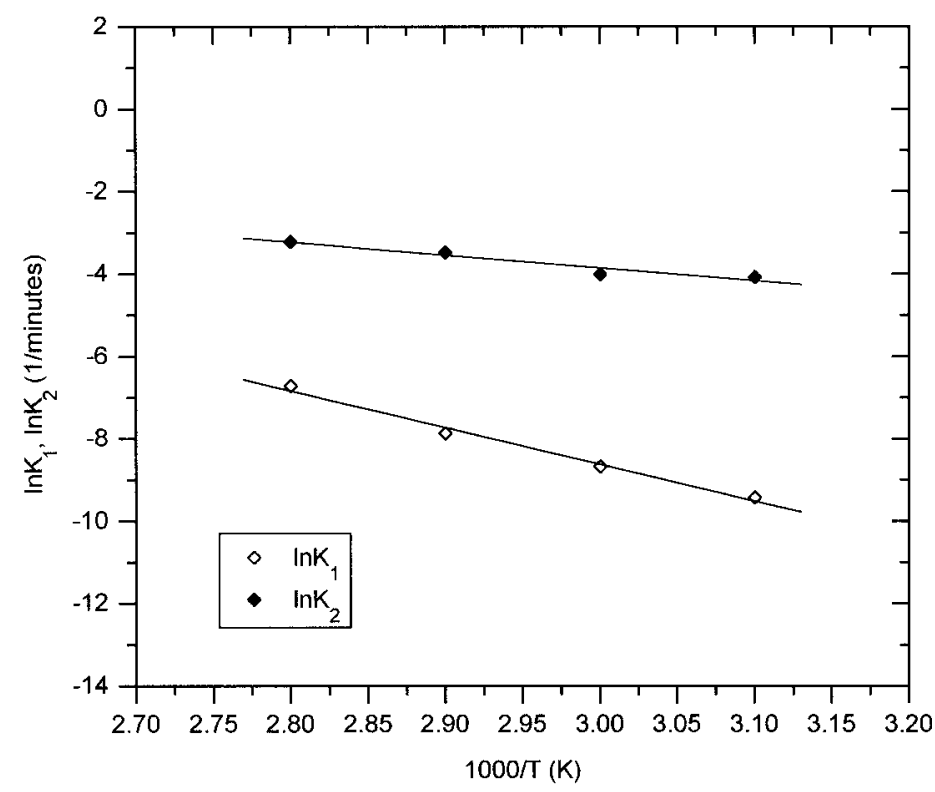

Figure 6 Arrhenius plot of rate constants, $\ln K_{1}$ and $\ln K_{2}$.

$$
K_{1}=A_{1} \exp \left(\frac{-E_{1}}{R T}\right), \quad K_{2}=A_{2} \exp \left(\frac{-E_{2}}{R T}\right)
$$

found to behave as linear functions of the cure temperature as shown in Figure 5. The two linear functions are given in eq. (6):

$$
\begin{gathered}
m=1.302-0.003 \times T(K) \\
n=2.528-0.011 \times T(K)
\end{gathered}
$$

The rate constants $K_{1}$ and $K_{2}$ are displayed as a function of temperature in Figure 6. In Figure 6,

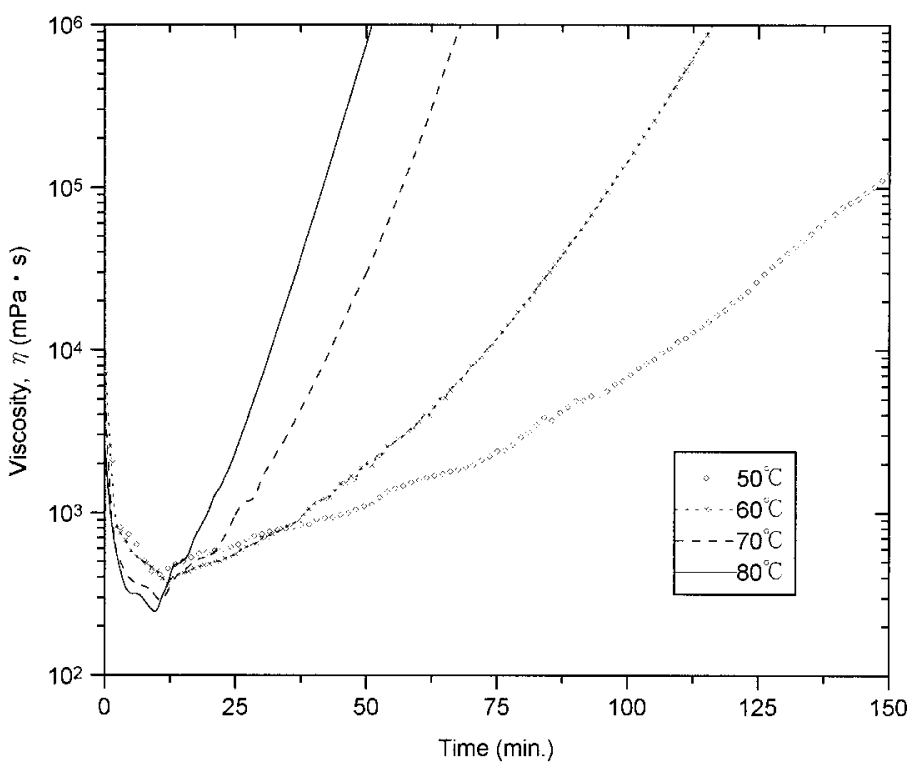

Figure 7 Viscosity profiles as a function of time at different temperatures. 
Table II Properties of LY564/HY2954 Epoxy/ Amine Resin at Gel Point

\begin{tabular}{cccc}
\hline $\begin{array}{c}\text { Temperature } \\
\left({ }^{\circ} \mathrm{C}\right)\end{array}$ & $\begin{array}{c}\text { Degree } \\
\text { of Cure } \\
\alpha_{\text {gel }}\end{array}$ & $\begin{array}{c}\text { Viscosity } \\
\eta_{\text {gel }}(\mathrm{mPa} \mathrm{s})\end{array}$ & $\begin{array}{c}\text { Gel Time } \\
t_{\text {gel }}(\mathrm{min})\end{array}$ \\
\hline 50 & 0.74 & $1.6 \mathrm{E} 07$ & 207 \\
60 & 0.72 & $1.7 \mathrm{E} 07$ & 138 \\
70 & 0.72 & $2.0 \mathrm{E} 07$ & 86 \\
80 & 0.74 & $2.8 \mathrm{E} 07$ & 60 \\
\hline
\end{tabular}

the values of $A_{1}, A_{2}, E_{1}$, and $E_{2}$ in eq. (5) were obtained from the intercepts and slope of the lines fitting to the $K_{1}, K_{2}$ versus $1 / T$ points. They are $7.30 \times 10^{7} \mathrm{~min}^{-1}, 2.53 \times 10^{2} \mathrm{~min}^{-1}, 74.23 \mathrm{~kJ} / \mathrm{mol}$, and $26.03 \mathrm{~kJ} / \mathrm{mol}$, respectively. Thus, the rate of the reaction $d \alpha / d t$ for the LY564/HY2954 epoxy/ amine resin can be obtained in the following form:

$$
\begin{aligned}
\frac{d \alpha}{d t}= & \left(7.30 \times 10^{7} \exp \left(-\frac{8.93 \times 10^{3}}{T}\right)+2.53\right. \\
& \left.\times 10^{2} \exp \left(-\frac{3.13 \times 10^{3}}{T}\right) \alpha^{1.302-0.003 \times T}\right) \\
& \times\left(\alpha_{\max }-\alpha\right)^{2.528-0.011 \times T}
\end{aligned}
$$

In Figure 4, the experimental data of $d \alpha / d t$ are compared to values of empirical prediction by eq. (7) as a function of the degree of cure $\alpha$. A reasonably good agreement was observed over the temperature range of $50-80^{\circ} \mathrm{C}$. Furthermore, a max- imum reaction rate that occurred at about $\alpha$ $=0.15$ as a consequence of the autocatalytic behavior is also clearly presented in Figure 4.

\section{Rheological Behavior}

The viscosity is a measure of the resin's resistance to flow and an indication of the degree of cure in the RTM process. The viscosity profile of the LY564/HY2954 epoxy resin as a function of time at different temperatures ranging from 50 to $80^{\circ} \mathrm{C}$ is given in Figure 7. Upon heating, the viscosity of the resin decreases rapidly, showing a minimum value below $1000 \mathrm{mPa}$ s for a certain time period, and then the viscosity experiences a sharp rise toward the gel points. At higher temperatures, the viscosity of the resin became lower initially, but increased earlier due to the curing. Hence, at an elevated temperature, the impregnation of fabrics by the resin is facilitated initially, but the time (filling time) for the viscosity of the resin remaining below $1000 \mathrm{mPa}$ s that is suitable for the mold filling is reduced. The time required to reach the gel point, viscosity at the gel point, and the degree of cure at the gel point of the LY564/HY2954 resin at various temperatures are given in Table II. Apparently, an increase in temperature of the resin in the mold-filling process leads to a higher gel viscosity and a reduced gel time. The degree of cure at gelation remains a constant of 0.73 on average. The resin viscosity can be described by an empirical model, ${ }^{17}$ accounting for the temperature and the curing kinetics effects. In this model, the viscosity is a

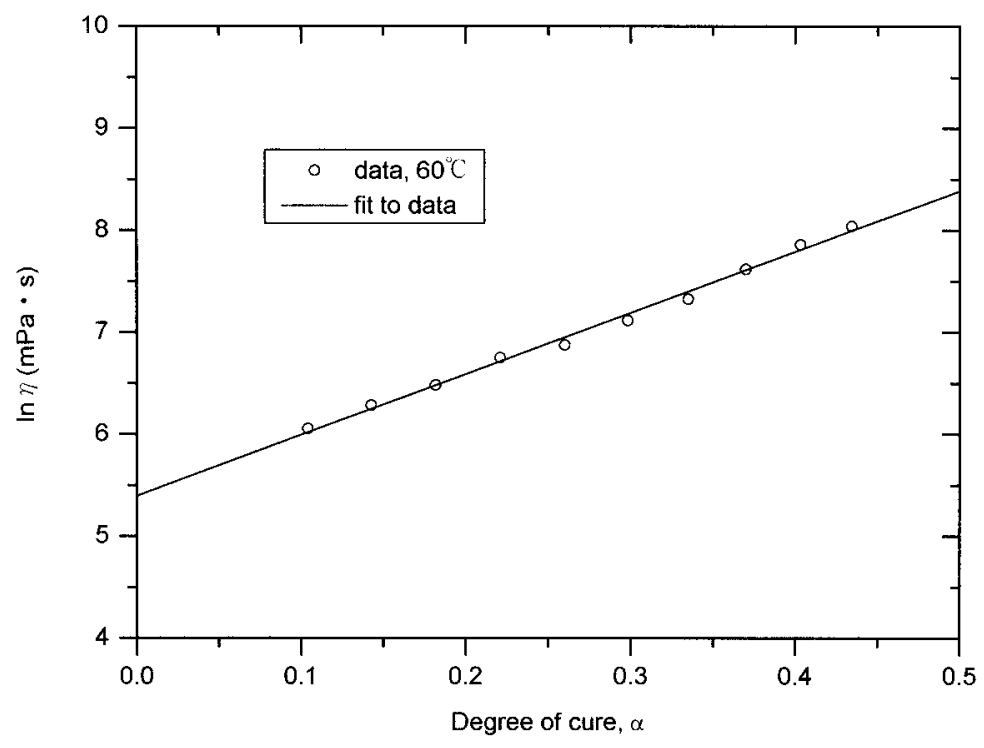

Figure 8 Viscosity as a function of degree of cure, $\alpha$, at $60^{\circ} \mathrm{C}$. 
Table III Temperature-dependent Constant $\kappa$ in Eq. (8)

\begin{tabular}{ccccc}
\hline & \multicolumn{4}{c}{ Temperature } \\
\cline { 2 - 5 } Constant & $50^{\circ} \mathrm{C}$ & $60^{\circ} \mathrm{C}$ & $70^{\circ} \mathrm{C}$ & $80^{\circ} \mathrm{C}$ \\
\hline$\kappa$ & 4.654 & 5.988 & 7.605 & 8.080 \\
\hline
\end{tabular}

function of the temperature and the degree of cure expressed in the following form:

$$
\eta(T, \alpha)=\eta_{0} \exp \left(\frac{U}{R T}+\kappa \alpha\right)
$$

where $\eta_{0}$ and $\kappa$ are constants; $U$, the activation energy of the viscous flow; $R$, the gas constant, and $T$, the absolute temperature. The constants $\eta_{0}$ and $\kappa$ can be determined by rearranged eq. (8) as

$$
\ln \eta=P+\kappa \alpha
$$

where $P$ is a parameter representing the initial nonreacting properties ${ }^{25}$ and is defined as

$$
P=\ln \eta_{0}+\left(\frac{U}{R}\right) \frac{1}{T}
$$

Then, $\ln \eta$ was plotted against the degree of cure $\alpha$ from the measured data. The viscosity against the degree of cure of the LY564/HY2954 epoxy/ amine resin at $60^{\circ} \mathrm{C}$ is displayed in Figure 8. The constant $\kappa$ can be obtained from the slope of a straight line fitted to the data in the plots at each temperature, as shown in Figure 8. The parameter $P$ is determined as the intercept of the straight line with the vertical axis. The value of $\kappa$ was found to be temperature-dependent as given in Table III. Similarly, $\eta_{0}$ and $U$ can also be determined from the intercept and the slope of a fitted linear line in a plot of $P$ versus $1 / T$, as shown in Figure 9. The resulting values of these parameters are as follows:

$$
\begin{aligned}
\eta_{0} & =8.74 \times 10^{-7} \mathrm{mPa} \mathrm{s} \\
\kappa & =-34.640+0.122 \times T(K) \\
U & =5.30 \times 10^{4} \mathrm{~J} / \mathrm{mol}
\end{aligned}
$$

As a result, the viscosity of the LY564/HY2954 epoxy/amine resin can be written as eq. (11):

$$
\begin{aligned}
& \eta=8.74 \times 10^{-7} \\
& \exp \left(\frac{6.37 \times 10^{3}}{T}+(-34.640+0.122 \times T) \times \alpha\right)
\end{aligned}
$$

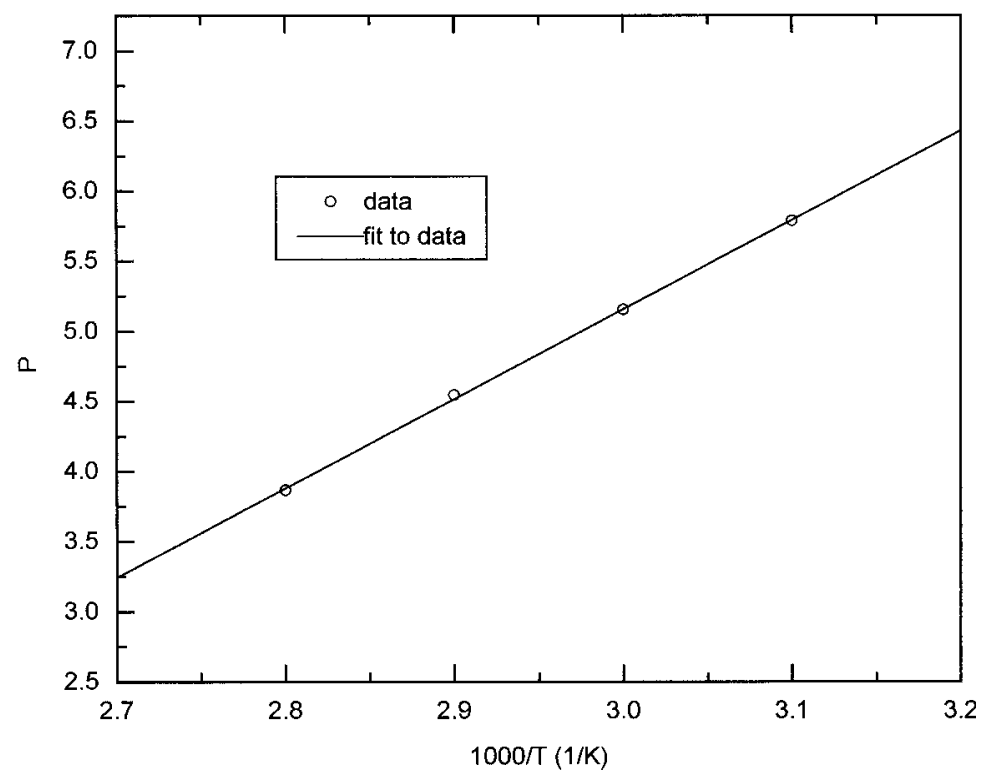

Figure 9 The parameter $P$ in eq. (10) as a function of inverse absolute temperature. 


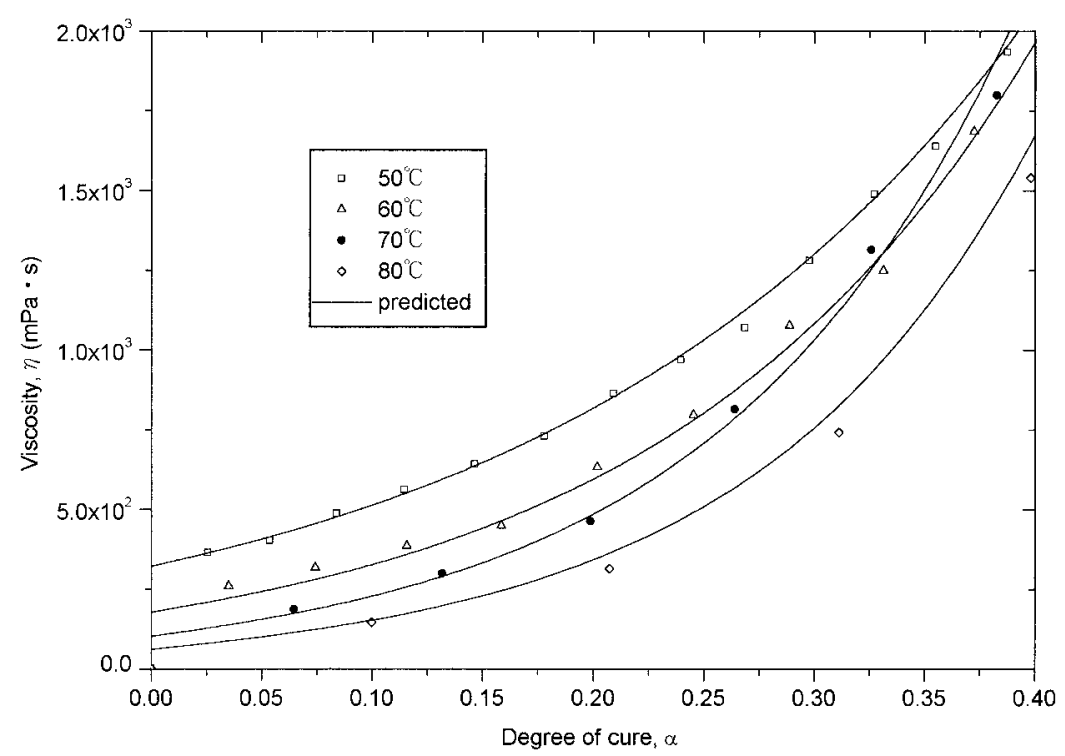

Figure 10 Comparison of experimental data with model predictions: viscosity versus degree of cure, $\alpha$, at different temperatures.

in which $T$ is in degrees Kelvin and $\eta$ is in $\mathrm{mPa}$ s. The comparison between the measured viscosity and the predicted viscosity by eq. (11) over the temperature range $50-80^{\circ} \mathrm{C}$ of the filling stages in the RTM process is shown in Figure 10. In Figure 10, the predicted viscosity by eq. (11) agrees well with the measured viscosity up to the degree of cure $\alpha=0.4$, accounting for the whole filling stage for the RTM process of the LY564/ HY2954 resin.

\section{CONCLUSIONS}

The curing kinetics of a two-part epoxy/amine resin for mold filling in the RTM processing was analyzed using DSC. A Kamal kinetic model modified with temperature-dependent parameters accounting for the autocatalytic and the diffusion effects in the curing reaction was derived. The model parameters were obtained through isothermal and dynamic DSC analyses in the temperature range $50-80^{\circ} \mathrm{C}$. An empirical model was adapted to describe the resin viscosity as a function of temperature and the degree of cure for the filling stage of the RTM process. A reasonably good agreement between the predicted and the measured values of viscosity was obtained for the mold-filling stage.
The authors are grateful for the financial support of this study from the National Science Council of Taiwan, Republic of China (Grant NSC 87-2623-D-009-005).

\section{REFERENCES}

1. Stover, D. High-Perform Compos 1994, Jul/Aug, 18-21.

2. Karlsson, K. F.; Astrom, B. T. Composites A 1997, $28,97-111$.

3. Beckwith, S. W.; Hyland, C. R. SAMPE J 1998, 34, 7-19.

4. Spoerre, J.; Zhang, C.; Wang, B.; Panas, R. J Compos Mater 1998, 32, 1244-1272.

5. Foley, M. F. SAMPE Q 1991, Jan, 61-68.

6. Michaud, D. J.; Beris, A. N.; Dhurjati, P. S. J Compos Mater 1998, 32, 1273-1296.

7. Lin, R. J.; Lee, L. J.; Liou, M. J. Polym Compos 1993, 14, 71-81.

8. Kamal, M. R.; Sourour, S. Polym Eng Sci 1973, 13, 59-64.

9. Yousefi, A.; Lafleur, P. G.; Gauvin, R. Polym Compos 1997, 18, 157-168.

10. Halley, P. J.; Mackay, M. E. Polym Eng Sci 1996, 36, 593-609.

11. Cole, K. C.; Hechler, J. J.; Noel, D. Macromolecules 1991, 24, 3098-3110.

12. Khanna, U.; Chanda, M. J. Appl Polym Sci 1993, 49, 319-329.

13. Barral, L.; Cano, J.; Lopez, A. J.; Lopez, J.; Nogueira, P.; Ramirez, C. J Appl Polym Sci 1995, 56, 1029-1037.

14. Kenny, J. M. Compos Struct 1994, 27, 129-139. 
15. Kenny, J. M.; Trivisano, A. Polym Eng Sci 1991, 31, 1426-1433.

16. Kenny, J. M.; Maffezzoli, A.; Nicolais, L. Compos Sci Technol 1990, 38, 339-358.

17. Stolin, M. A.; Merzhanov, A. G.; Malkin, A. Y. A. Polym Eng Sci 1979, 19, 1074-1080.

18. Phelan, F. R., Jr. Polym Compos 1997, 18, 460-476.

19. Cai, Z. J Compos Mater 1992, 26, 1310-1338.

20. Parnas, R. S.; Salem, A. J. Polym Compos 1993, 14, 383-394.
21. Kendall, K. N.; Rudd, C. D. Polym Compos 1994, 15, 334-348.

22. Chan, A. W.; Hwang, S. T. Polym Eng Sci 1991, 31, 1149-1156.

23. Lee, C. L.; Ho, J. C.; Wei, K. H. Polym Eng Sci, accepted.

24. Olivier, P.; Ioualalen, K.; Cottu, J. P. J Appl Polym Sci 1997, 63, 745-760.

25. Lane, J. W.; Khattack, R. K. SPE ANTEC Tech Pap 1987, 33, 982-986. 